\title{
Summary of Current and Future MSFC International Space Station Environmental Control and Life Support System Activities
}

Charles D. Ray and Robyn L. Carrasquillo NASA Marshall Space Flight Center

Silvia Minton-Summers ION Electronics 
SAE routinely stocks printed papers for a period of three years following date of publication. Direct your orders to SAE Customer Sales and Satisfaction Department.

Quantity reprint rates can be obtained from the Customer Sales and Satisfaction Department.

To request permission to reprint a technical paper or permission to use copyrighted SAE publications in other works, contact the SAE Publications Group.

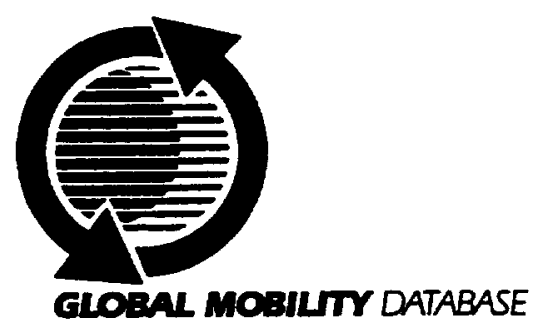

All SAE papers, standards, and selected books are abstracted and indexed in the Global Mobility Database.

\section{ISSN 0148-7191}

Positions and opinions advanced in this paper are those of the author(s) and not necessarily those of SAE. The author is solely responsible for the content of the paper. A process is available by which discussions will be printed with the paper if it is published in SAE Transactions. For permission to publish this paper in full or in part, contact the SAE Publications Group.

Persons wishing to submit papers to be considered for presentation or publication through SAE should send the manuscript or a 300 word abstract of a proposed manuscript to: Secretary, Engineering Meetings Board, SAE. 


\title{
Summary of Current and Future MSFC International Space Station Environmental Control and Life Support System Activities
}

\author{
Charles D. Ray and Robyn L. Carrasquillo \\ NASA Marshall Space Flight Center \\ Silvia Minton-Summers \\ ION Electronics
}

\begin{abstract}
This paper provides a summary of current work accomplished under technical task agreement (TTA) by the Marshall Space Flight Center (MSFC) regarding the Environmental Control and Life Support System (ECLSS) as well as future planning activities in support of the International Space Station (ISS). Current activities include ECLSS computer model development, component design and development, subsystem/integrated system testing, life testing, and government furnished equipment delivered to the ISS program. A long range plan for the MSFC ECLSS test facility is described whereby the current facility would be upgraded to support integrated station ECLSS operations. ECLSS technology development efforts proposed to be performed under the Advanced Engineering Technology Development (AETD) program are also discussed.
\end{abstract}

\section{INTRODUCTION}

MSFC was assigned responsibility for space station ECLSS design and development in 1984. Activities completed during space station Phase $B$ and $C / D$ included ECLSS design, analysis, and in-house testing. Under ECLSS design, MSFC was responsible for the six major ECLSS functions, specifications and standards, component design and development, and was the architectural control agent for the space station ECLSS. MSFC was responsible for ECLSS analytical model development and conducted subsystem and system level analyses. In-house subsystem and system level testing was conducted in support of the design process. This included testing of air revitalization, water reclamation and management hardware, and certain non-regenerative systems.

All the activities described in this paper were approved in task agreements between the MSFC and the NASA Headquarters Space Station Program Management Office at Johnson Space Center and Boeing, their prime contractor for the ISS. These MSFC activities are in-line to the designing, development, testing, and flight of ECLSS equipment planned by the Boeing Company in Huntsville, supporting the prime contractor, Boeing, in Houston. MSFC's unique capabilities for performing integrated systems testing and analyses, and its ability to perform some tasks cheaper and faster to support ISS program needs are the basis for the TTA activities.

Tasks were completed in the water recovery systems and air revitalization (AR) systems areas. The tasks in the water recovery and air revitalization areas were divided into analytical model development, component design and development, subsystem and integrated systems testing, life testing, and government-furnished equipment items. The results of each of these tasks are described in this paper.

Proposals were made to the ISS Program Office in the areas of sustaining engineering and ECLSS technology development. An upgrade to the current facility was proposed with the addition of a habitation module simulator and development hardware to support on-orbit operations. Seven AETD proposals were submitted which would utilize the current facility to test evolution of current baselined ECLSS subsystems.

\section{ORGANIZATION}

Organizations which support TTA activities and the interfaces are shown in figure 1. The Environmental Control and Life Support Branch of the Structures and Dynamics Laboratory within Science and Engineering (S\&E) Directorate of MSFC manage the overall ECLSS TTA work. Within the Environmental Control and Life Support Branch, engineers were assigned responsibilities to develop test requirements, perform analyses of test results, support actual testing, and manage special tasks performed under the ECLSS test services contract. The Development and Environmental Test Branch of the Systems Analysis and Integration Laboratory in S\&E provides the test facilities and performs the ECLSS testing at MSFC. Test subjects from various organizations exercised in the End-use Equipment Facility (EEF) to generate metabolic waste products for the Stage 10 water reclamation testing. The test services contractor, ION Electronics, provides test support, analytical modeling of the integrated test configurations, test support and studies from the ECLSS subcontractors, 
and analytical model development. Key Boeing-Huntsville support to MSFC integrated systems testing is the chemical/microbial laboratory analyses of air and water samples. Overall results of the Boeing-Huntsville chemical/microbial laboratory analyses and the sensor data are maintained in a database developed by MSFC and utilized by all space station participants. Products provided to the ISS program include computer models, reports, and test reports/findings.

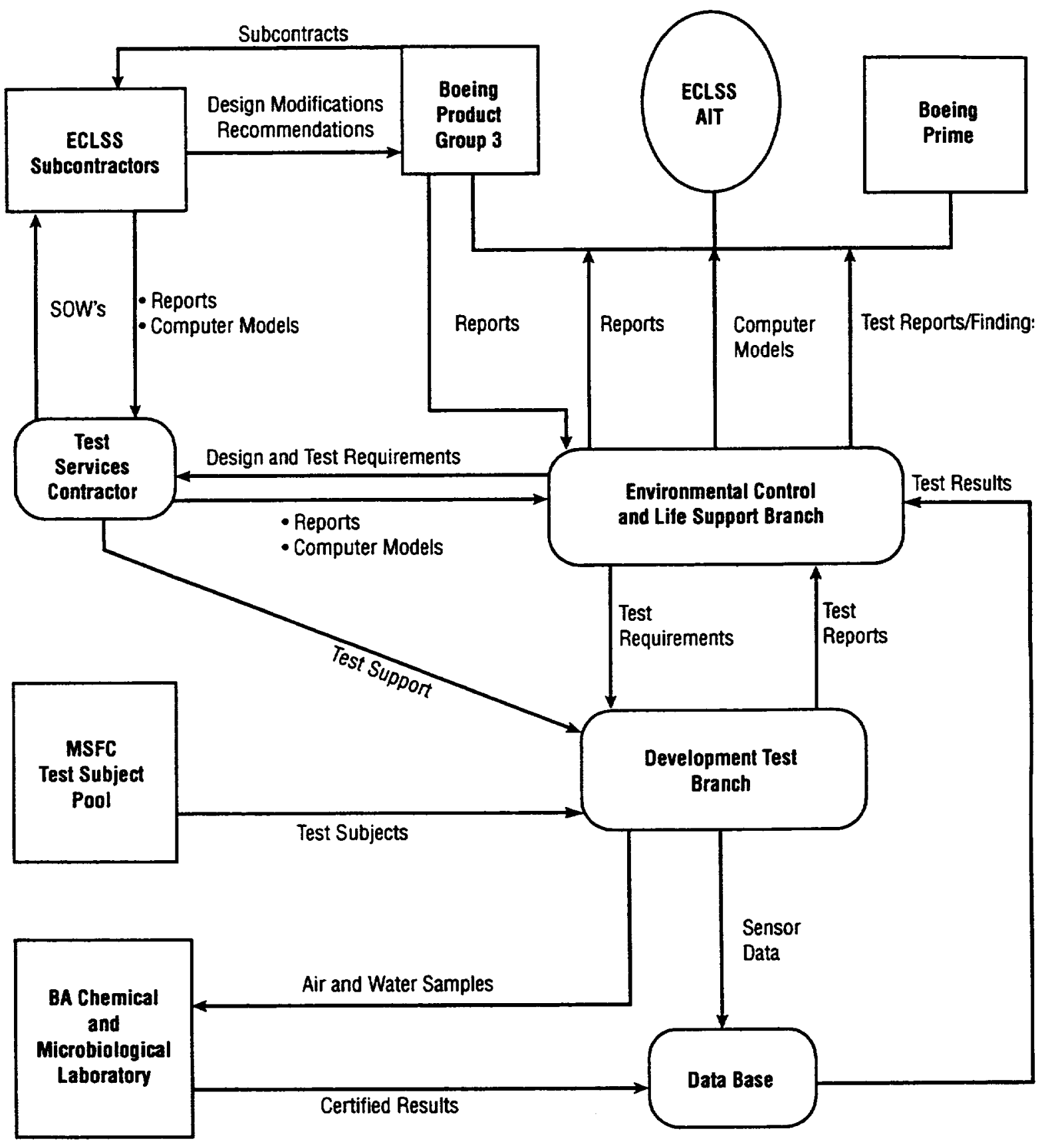

Figure 1.-MSFC ECLSS Technical Task Agreement organizational interfaces. 


\section{COMPONENT DESIGN AND DEVELOPMENT}

There are several outstanding design issues associated with components in the United States (U.S.) habitation module water recovery systems which required early development attention. These include the water processor (WP) process pump, WP mostly liquid separator, and the urine pretreatment injection system.

PROCESS PUMP [1]-The process pump is an integral part of the ISS water processor (figure 2). The process pump's function is to supply the system's flow rate and operating pressure through the multifiltration (MF) beds and the volatile removal assembly (VRA) which represent the two techniques for removing contaminants from the waste water. First, waste water is treated via multifiltration technology, which utilizes a series of ion exchange resins and carbonaceous or polymeric adsorbents packaged to optimally remove ionic compounds and some organics. The VRA is a component in the water processor with the function of oxidizing organics that are not removed by the MF bed ion exchange technology. Early development testing indicated that the MF bed media did not have the capability to remove low molecular weight organics and the VRA was added to the design.

In early 1992, Hamilton Standard evaluated a prototype process pump with two identical nitrited 7-4PH stainless steel (SS) gear pump assemblies. Testing efforts were terminated due to high motor temperature and no flow conditions indicating pump failure. Particles from a corroded test-rig plug flowed into the pump and caused gear lockup. Internal evaluations of the pump head concluded that the corrosion resistance of the gear and cartridge materials needed to be improved to meet the life requirements.
An effort began under ECLSS supporting development in March 1994 and concluded in July 1995 to continue development of the process pump by significantly improving the corrosion resistance, while still meeting the mechanical requirements of the pump. The first gear materials evaluated included Inconel 718 and 15-5 PH SS. Subsequent testing indicated that the surface hardness of both gear materials was too low to provide adequate life in the nonlubricating fluid. A new action plan was developed where the 15-5 SS gears were tested at lower speeds and two new gear sets were fabricated and tested (borided Inconel 718 and borided cobalt alloy Stellite 6B). Test results indicated that none of these options significantly increased life over previous options tested.

A follow-on ECLSS supporting development effort was initiated in November 1995 to examine alternate pump technologies other than a gear pump design. A trade study based on the quality function deployment (QFD) technique indicated that four technologies rated highest: gear, piston, diaphragm, and vane pumps. Pump designs were solicited from industry with companies selected to develop designs and deliver prototype pumps for each technology. The diaphragm pump winner was an off-the-shelf item. All prototype pumps have been delivered and currently are being tested. Initial test results are encouraging with three of the pumps having operated in excess of 1200 hours with no indication of performance degradation. Selection criteria will be developed and at the conclusion of testing a single pump will be selected as the baseline.

MOSTLY LIQUID SEPARATOR [1]-The mostly liquid separator (MLS) is another integral part of the ISS WP (figure 2). The WP waste water contains free gas

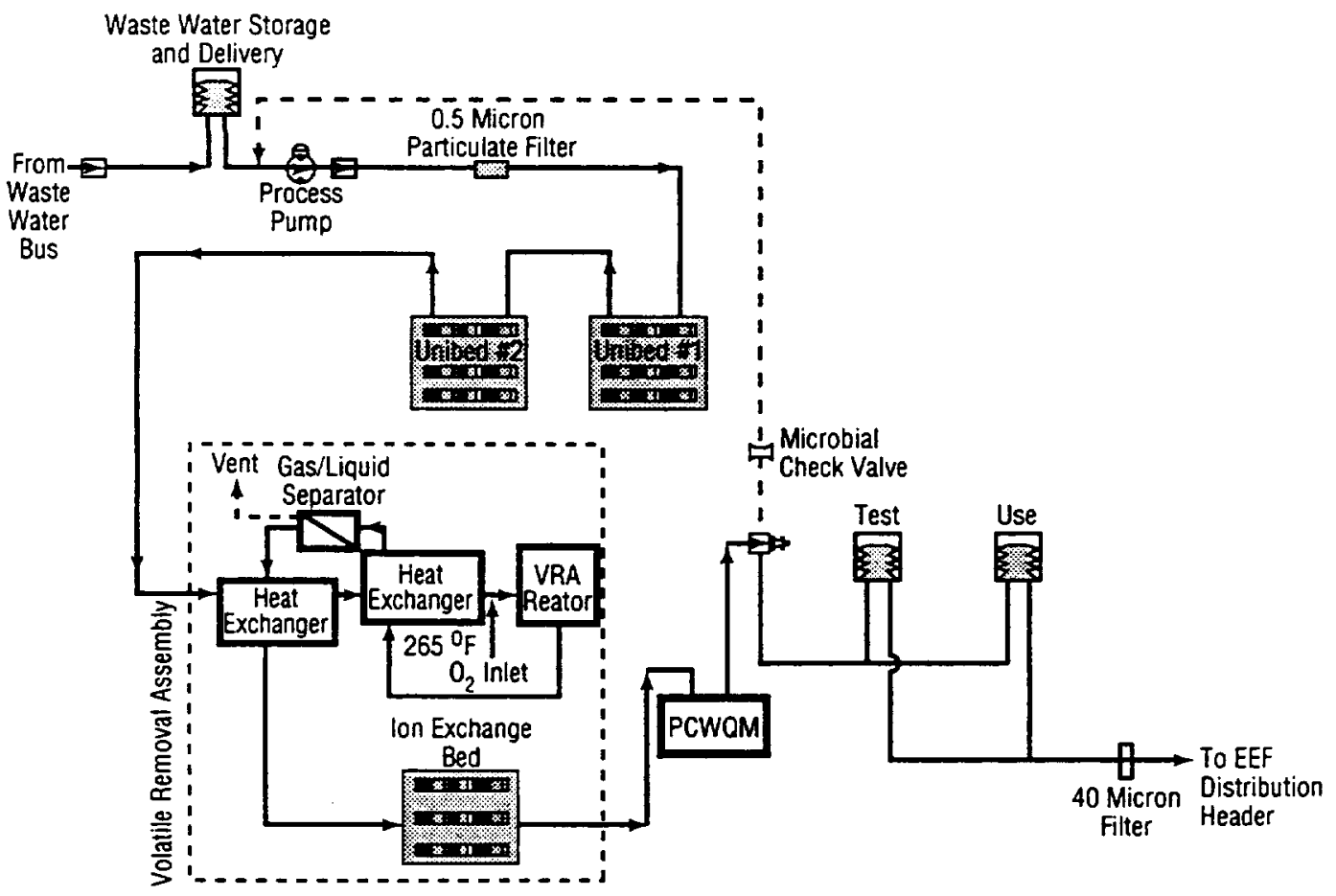

FIGURE 2.-Water processor assembly schematic 
along with other materials which cause foaming. If the gas is not removed the system becomes "gas-locked" which results in degradation of the system's performance. The MLS removes free gas from the waste water prior to storage or processing by the water processor. Hamilton Standard built and tested an initial MLS unit for the potable water processor which used a series of low speed paddles and a high speed screen coalesce. When the space station design changed to a single water processor, the design changed to a series of cylindrical disks. This design was tested using different feed water compositions with varied free gas concentrations. Although there were modifications incorporated into the MLS design during testing, results indicated that the design provided gas/liquid separation and insignificant foaming.

An effort was completed under ECLSS supporting development to further develop the MLS technology, characterize its performance, and define its operating requirements. A new MLS design was created, translucent plastic prototype units fabricated, and performance tested. Several hardware modifications were made during testing resulting in better performance. Test results indicated that maintaining a near constant backpressure and revolutions per minute (rpm) within the MLS was of prime importance in providing acceptable performance.

A follow-on effort was initiated to incorporate recommended modifications to the MLS design and test stand, test the previous MLS design with the test stand modifications, and build and test one full size MLS with a clear plastic housing. The previous MLS was tested with the test stand modified to maintain backpressure and with a constant direct drive motor utilized to remove any loss in rpm. These modifications resulted in improved MLS performance. Testing of the full size MLS is underway and should be completed in late summer 1997.
URINE PRETREATMENT INJECTION SYSTEM [1]Urine pretreatment, as presently defined for the space station program for proper downstream processing of urine, is a two-part chemical treatment of OXONE ${ }^{\mathrm{TM}}$ and sulfuric acid.

A program was devised to develop and test the best method of injection of OXONE ${ }^{T M}$ into the urine collection system. Trade study results indicated that the best method was a solid tablet in a bag suspended in the urine/air stream. A successful fabrication technique was developed for retaining the tablets in a fabric casing attached to the end of the existing Space Station Waste Collection system urine prefilter assembly. A test to prove the concept was conducted using the urine fan/separator assembly originally used in the STS-52 Design Test Objective (DTO) urinal assembly. Test results indicated that an average pretreatment ratio of 5.2 grams $(\mathrm{g})$ of OXONE ${ }^{\mathrm{TM}}$ per liter was obtained meeting the program goal of $5.0 \mathrm{~g} /$ liter.

A follow-on effort investigated the best method for injection of sulfuric acid. A solid tablet was developed using potassium bisulfate to hold the sulfuric acid in the tablet. $A$ design configuration (figure 3) with OXONE ${ }^{\mathrm{TM}}$ and sulfuric acid tablets was selected. An effort is in progress to investigate development issues such as storage of the tablets, material compatibility, and preparation of the sulfuric acid tablets.

\section{COMPUTER MODEL DEVELOPMENT}

Analytical models are being developed for components of the WP as well as the Four Bed Molecular Sieve (4BMS). Water processor components being modeled include the MF beds and the VRA reactor. The MF bed and VRA function were described in a previous section of this paper. An integrated 4BMS model is also being developed.

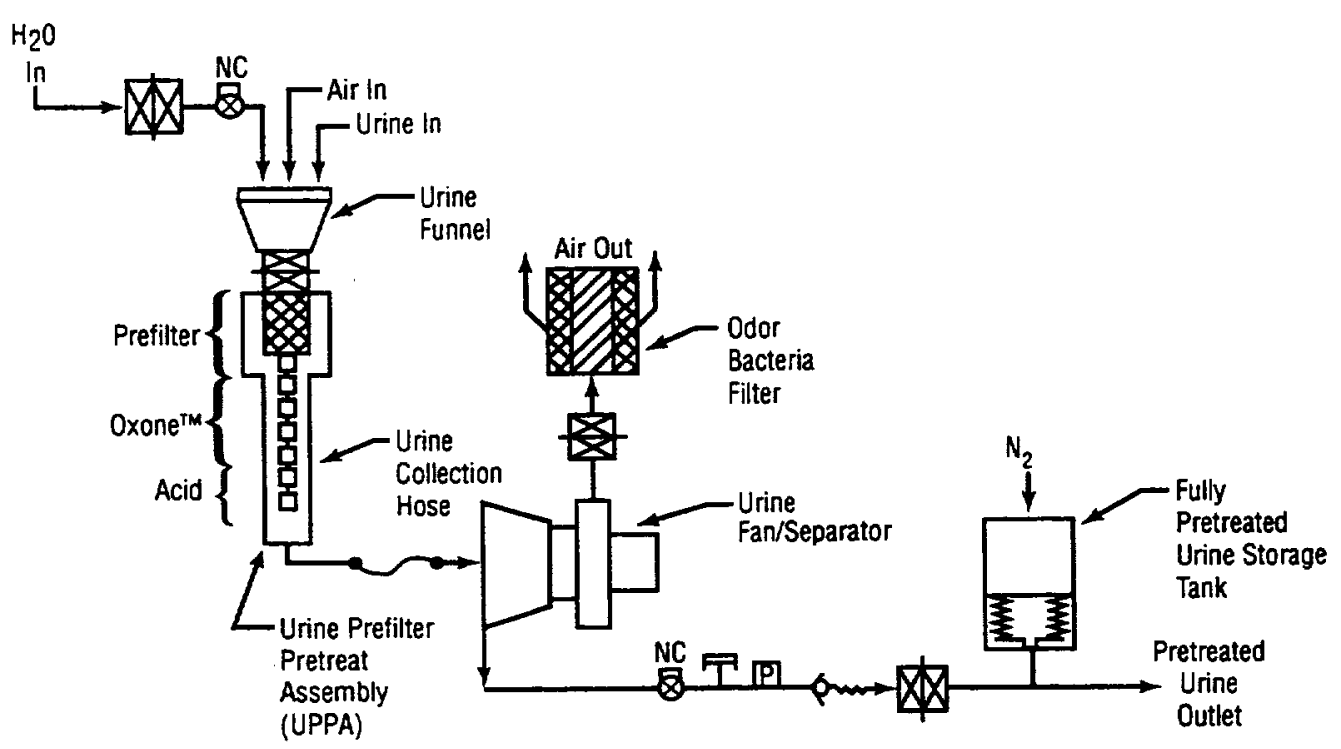

FIGURE 3.-Space station urine pretreatment concept. 
MULTIFILTRATION BEDS-This effort will result in the development of a computer model capable of defining MF bed performance in terms of contaminant removal efficiency and life expectancy with varying input conditions. Upon completion, this model will be used to predict performance capabilities rather than running a test for the specific waste stream conditions. Currently when waste stream conditions are changed, a test has to be conducted for the new waste stream composition to determine MF bed performance and life capabilities.

Recognizing the need for this type model, MSFC contracted with Michigan Technological University in 1992 to model the performance of the potable loop humidity condensate MF bed. This model had limited application but did provide valuable information necessary to define the steps to develop an MF model for a single loop processor. This effort was divided into two phases (I and II). During phase I [2], the model was developed for only shower/ handwash waste water. The phase I effort addressed the performance of the ion exchange resins, including equilibrium and kinetic studies, as well as development of an ion exchange model and a pore and surface diffusion model to describe adsorption kinetics.

The objective of the ongoing phase $\|$ effort is to develop a model that will predict MF bed performance for all ISS waste streams. Both adsorption and ion exchange models are being developed with each including equilibrium and kinetic descriptions. Work completed during phase $I$ is being used as the basis for these models. Upon completion of the models, test data from a MF fixed bed column with sample ports between each adsorbent and ion exchange resin installed in the MSFC stage 10 water recovery test will be used to make a final calibration of the models.

VOLATILE REMOVAL ASSEMBLY - A VRA model is being developed capable of predicting catalytic oxidization performance based on varying waste water contaminant loads. The importance of the catalytic oxidation process in meeting the potable water quality specification leads to the necessity of predicting its performance based on varying contaminant loads. Without a model of this type, tests must be run every time VRA input conditions are changed. These input conditions include varying the contaminant load and load duration in terms of process water throughput, reactor residence time (i.e., catalyst volume), pressure, and temperature.

This effort was divided into phases I and II. During phase I [3,4] a multiphase, multicomponent reactor model for five contaminants was developed. This model's predictions were similar to actual experimental results for urea, chlorobenzene, and ethanol over the range of conditions. The results for formaldehyde indicated that its destruction rate was entirely limited by the rate of mass transfer. Dimethyl sulfoxide acted as a weak poison at lower temperatures, and the prediction of conversions was poor. The phase $I I$ effort is following a path similar to that of phase 1 . The combination of an experimental program on a test reactor and a computer based numerical approach to first fit kinetic rate constants is being used to model the more complex behavior. The end product will be a multicomponent model for all potential contaminants.

FOUR BED MOLECULAR SIEVE-A schematic of the 4BMS is shown in figure 4. Major components include two desiccant beds, two adsorbent beds, a blower, a precooler, six selector valves, two check valves, and an air pump. Carbon dioxide $\left(\mathrm{CO}_{2}\right)$ laden air is directed through the subsystem by a blower. To prevent water vapor from poisoning the $\mathrm{CO}_{2}$ sorbent material, the air stream passes through a desiccant bed for water adsorption. The air stream is cooled to increase the $\mathrm{CO}_{2}$ removal capability, then passes through the $\mathrm{CO}_{2}$ sorbent bed. The $\mathrm{CO}_{2}$ beds are regenerated using thermal/pressure swing desorption, with the heat transferred to the desiccant bed undergoing water vapor desorption. The subsystem operates in an open loop configuration with the desorbed $\mathrm{CO}_{2}$ being vented overboard.

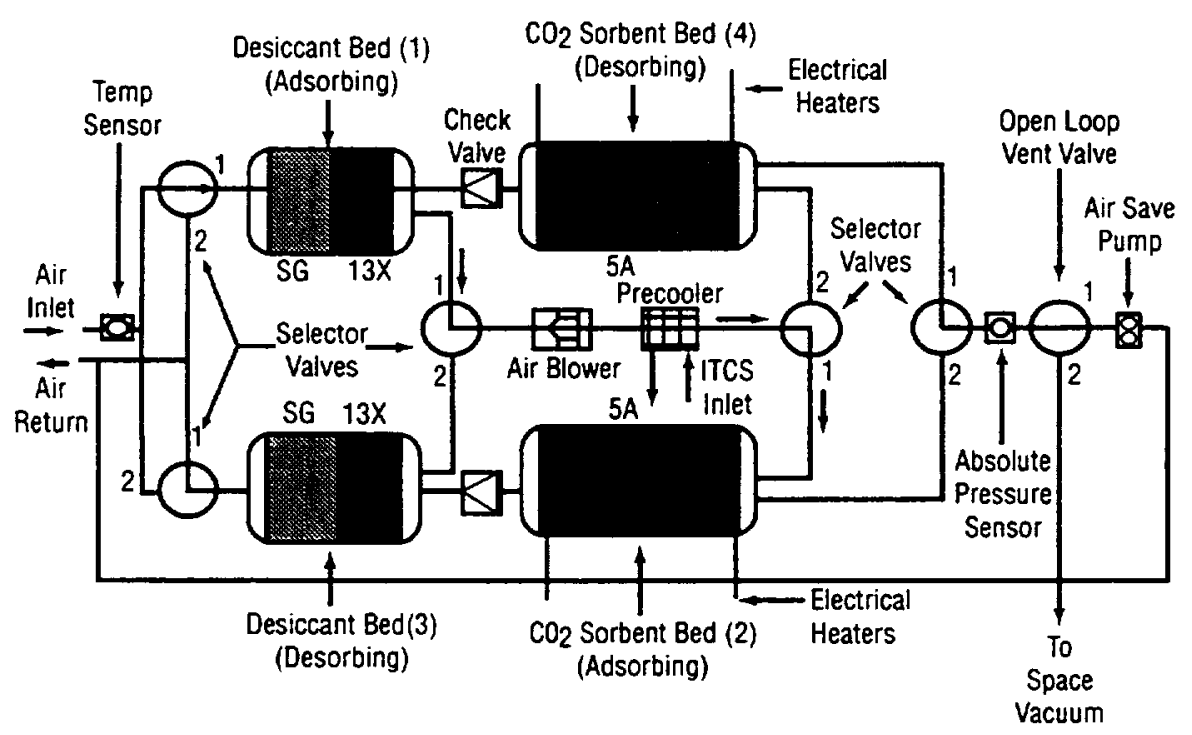

FIGURE 4.-Four-bed molecular sieve schematic. 
Single-Bed Models [5] were developed which simulated gas adsorption in a flow-through bed. Multicomponent adsorption; thermal balances for the pellet, gas, and canister; and the momentum equation were included. A two-dimensional (radial and axial) model was also developed to predict effects of flow channeling based on bed geometry. Another model incorporated multiple sorbent material layers. The final model simulated the thermal and vacuum regeneration of the $5 \mathrm{~A}$ bed.

Integration of the verified single-bed models is being performed at MSFC. A stand-alone version is being developed featuring transportability to any computer platform with a FORTRAN 77 compiler. This version will utilize simplified heat exchanger and blower components and will be limited to bed configurations matching the existing 4BMS configuration.

Conversion of the single-bed models to computer aided system engineering and analysis (CASE/A) will follow development of the stand-alone 4BMS model. CASE/A, a graphical-based system-level computer modeling tool, will allow much greater flexibility in configuration of the sorbent models. The 4BMS CASE/A model will be developed using the graphical user interface and existing CASE/A components such as heat exchangers, valves, blowers, controllers, and timers. Other $\mathrm{CO}_{2}$ removal system configurations can be readily developed based on the verified single-bed models in CASE/A to analyze candidate technologies for the evolutionary space station and future manned missions.

\section{SUBSYSTEMINTEGRATED TEST PROGRAMS}

Current in-house MSFC ECLSS testing includes both independent subsystem and integrated testing. Perfor- mance testing of the 4BMS is ongoing, and the stage 10 integrated water recovery test is complete.

FOUR BED MOLECULAR SIEVE INDEPENDENT SUBSYSTEM TESTING-Four bed molecular sieve testing includes the performance enhancement test (PET) which is being conducted to determine the enhancement potential of performance to meet reduced carbon dioxide partial pressure $\left(\mathrm{ppCO}_{2}\right)$ exposure levels. In addition, certain tests are planned to address 4BMS "flight issues".

A preliminary PET [6] was conducted in August 1996 to provide initial data to verify that 4BMS operational changes could be made such that the Life Sciences requirement of 2.2 millimeters of mercury $(\mathrm{mmHg}) \mathrm{ppCO}_{2}$ was met. A high-fidelity $4 B M S$ was utilized for this testing. Testing was conducted in the Core Module Simulator (CMS) which is a part of the MSFC ECLSS Test Facility in Building 4755. Four Bed Molecular Sieve parameters of air process flow rate, cycle time, and sorbent bed heater set point temperature were varied to determine removal capability for the various operational configurations. Six operational configurations were evaluated in a period of fifteen consecutive days.

Preliminary results from the PET are shown in table 1 , along with other recent test results for comparison from the MSFC integrated air revitalization test [7] and the $\mathrm{CO}_{2}$ removal rate and electrical power consumption evaluation test [8] conducted by Allied Signal. PET results are from July 14-August 11, 1996. Review of the test data (table 1) indicates that process air flow rate has the greatest influence on $\mathrm{CO}_{2}$ removal capability. Carbon dioxide removal rate divided by inlet $\mathrm{CO}_{2}$ partial pressure is plotted against flow rate to illustrate this relationship (figure 5).

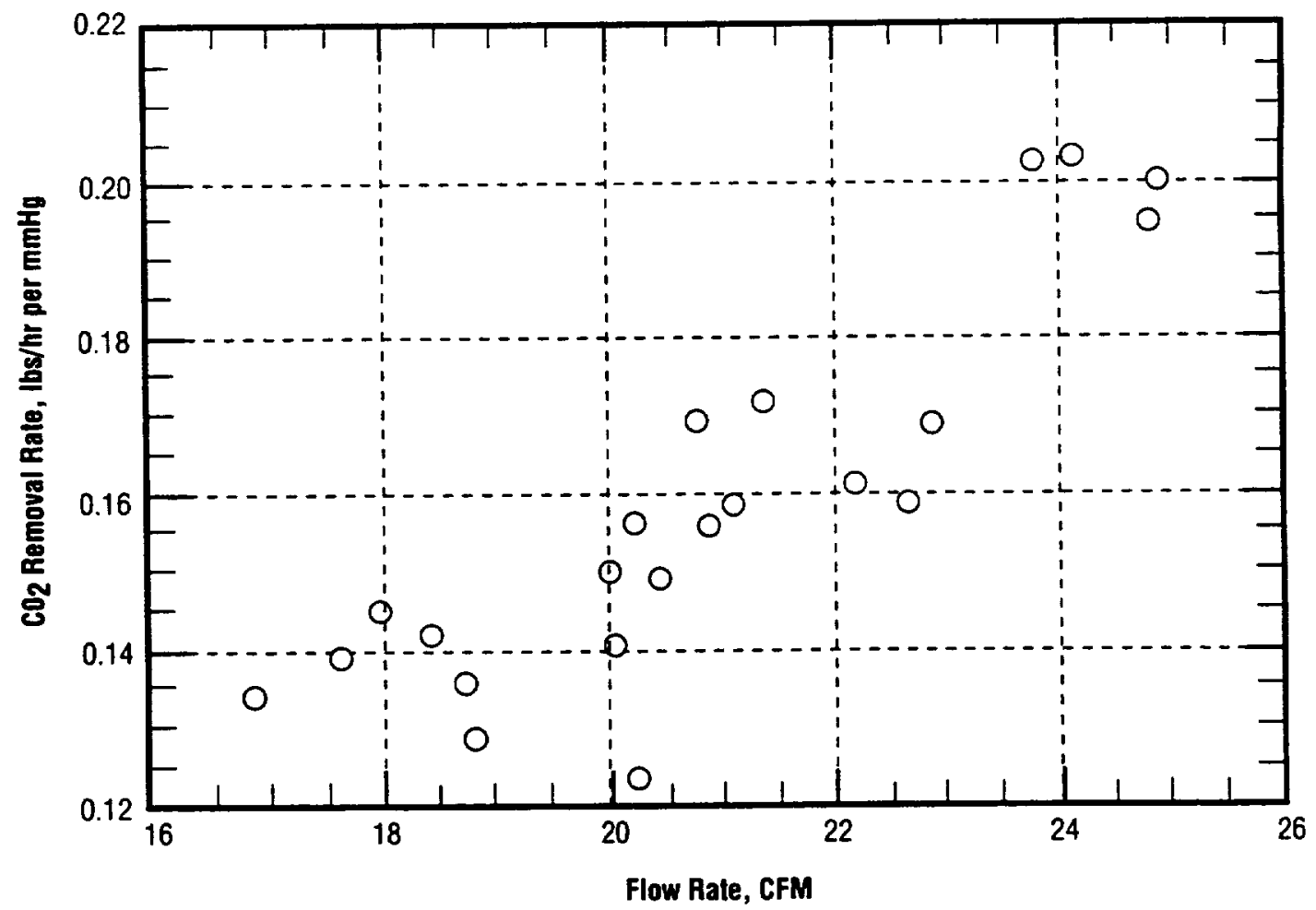

Figure 5. $-\mathrm{CO}_{2}$ removal versus flow rate. 
TABLE 1.-PET, IART, and development 4BMS results.

\begin{tabular}{|c|c|c|c|c|c|}
\hline Test Day & $\begin{array}{c}\text { Power } \\
\text { Mode: } \\
1=\text { Cont. } \\
2=0 / N\end{array}$ & $\begin{array}{c}1 / 2 \\
\text { Cycle } \\
\text { time, } \\
\text { minutes }\end{array}$ & $\begin{array}{c}\mathrm{CO}_{2} \\
\text { removal, } \\
\text { MEQ }\end{array}$ & $\begin{array}{l}\text { Flow } \\
\text { rate, } \\
\text { CFM } \\
\text { (MSFC }\end{array}$ & $\begin{array}{l}\text { Heater } \\
\text { set } \\
\text { point } \\
{ }^{\circ} \mathrm{F}\end{array}$ \\
\hline
\end{tabular}

MSFC Data

02/09/96

$02 / 22 / 96$

$03 / 01 / 96$

$03 / 14 / 96$

$03 / 27 / 96$

$04 / 11 / 96$

$07 / 14 / 96$

$07 / 28 / 96$

$07 / 30 / 96$

$08 / 04 / 96$

08/06/96

$08 / 08 / 96$

$08 / 11 / 96$

$\begin{array}{ll}1 & 160 \\ 2 & 160 \\ 2 & 144 \\ 2 & 144 \\ 2 & 144 \\ 2 & 144 \\ 2 & 144 \\ 2 & 144 \\ 2 & 160 \\ 2 & 144 \\ 1 & 144 \\ 1 & 144 \\ 2 & 144\end{array}$

$\begin{array}{ll}5.968 & 17.97 \\ 3.979 & 16.83 \\ 3.979 & 20.04 \\ 3.977 & 18.71 \\ 3.979 & 18.40 \\ 3.976 & 17.59 \\ 4.199 & 18.80 \\ 3.979 & 21.41 \\ 3.979 & 20.79 \\ 3.431 & 24.17 \\ 3.432 & 23.83 \\ 5.972 & 24.93 \\ 5.971 & 24.84\end{array}$

400
400
260
260
260
260
260
400
400
400
400
400
400

$\begin{array}{lll}3.77 & 0.547 & 0.15 \\ 2.72 & 0.365 & 0.13 \\ 2.59 & 0.365 & 0.14 \\ 2.69 & 0.365 & 0.14 \\ 2.57 & 0.365 & 0.14 \\ 2.62 & 0.364 & 0.14 \\ 2.99 & 0.385 & 0.13 \\ 2.12 & 0.365 & 0.17 \\ 2.15 & 0.365 & 0.17 \\ 1.54 & 0.315 & 0.20 \\ 1.55 & 0.315 & 0.20 \\ 2.73 & 0.547 & 0.20 \\ 2.80 & 0.547 & 0.20\end{array}$
$\underset{\text { removal }}{\mathrm{CO}_{2}} \underset{\text { removal }}{\mathrm{CO}_{2}} \quad \begin{gathered}\text { Water } \\ \text { loss, ib }\end{gathered}$
$\mathrm{lb} / \mathrm{hr}$ rate, $\mathrm{lb} / \mathrm{hr}$ /day
per $\mathrm{mmHg}$
based on
4BMS inlet

Power, Blower, Heater

AlliedSignal Data

$11 / 30 / 95 \quad 1 \quad 160$

$\begin{array}{llll}8.105 & 20.22 & 400 & 6.00 \\ 6.327 & 20.44 & 400 & 3.88 \\ 5.204 & 20.22 & 400 & 3.04 \\ 3.109 & 20.00 & 400 & 1.90 \\ 6.469 & 22.67 & 250 & 3.72 \\ 5.476 & 22.89 & 250 & 2.96 \\ 3.349 & 22.22 & 250 & 1.90 \\ 6.360 & 20.00 & 400 & 3.88 \\ 6.589 & 21.11 & 400 & 3.80 \\ 6.480 & 20.89 & 400 & 3.80\end{array}$

0.743
0.580
0.477
0.285
0.593
0.502
0.307
0.583
0.604
0.594

0.12
0.15
0.16
0.15
0.16
0.17
0.16
0.15
0.16
0.16

N/A
$N / A$
$N / A$
$N / A$
$N / A$
$N / A$
$N / A$
0.000
0.000
0.176
0.086
0.046
0.127

724

586

54

399

52

50

506

500

58

307

403

$482 \quad 59 \quad 387$

$489 \quad 57 \quad 396$

$493 \quad 58 \quad 399$

$641 \quad 86 \quad 515$

$633 \quad 86 \quad 515$

$652 \quad 110$

$821 \quad 109$

504

674

$828 \quad 109$

684

$680 \quad 109$

531

$12 / 07 / 95$

$12 / 09 / 95$

$12 / 11 / 95$

$12 / 13 / 95$

$12 / 16 / 95$

$12 / 18 / 95$

$01 / 25 / 96$

$01 / 30 / 96$

$1 / 31 / 96$

$$
\begin{aligned}
& 160 \\
& 160 \\
& 160 \\
& 144 \\
& 144 \\
& 144 \\
& 160 \\
& 160 \\
& 160
\end{aligned}
$$

6.480

N/A
N/A
$N / A$
$N / A$
$N / A$
$N / A$
$N / A$
$N / A$
$N / A$
N/A

$N / A$
658
658
658
556
566
566
817
743
658

$\begin{array}{ll}\text { N/A } & 521 \\ 148 & 449 \\ 140 & 448 \\ 148 & 446 \\ 163 & 343 \\ 163 & 318 \\ 163 & 312 \\ 148 & 607 \\ 148 & 535 \\ 148 & 444\end{array}$

Power Mode: For continuous power mode (cont.), no interruptions are made to the $5 \mathrm{~A}$ sorbent bed heater power during the test. For day/night cycling ( $\mathrm{D} /$ $\mathrm{N})$, the heater power is cycled off during a simulated orbital "night." These tests used an orbital cycle of 90 minutes and night duration of 37 minutes.

$1 / 2$ cycle time: duration of half the total 4 BMS cycle.

The 4BMS test setup has been upgraded with flight system sorbent beds, a commercial blower with higher flow rate capability, and facility upgrades to increase control over the process air dew point and temperature. Phase II PET testing will provide final performance enhancement data.

Four bed molecular sieve "flight issues" include-testing with 4BMS process air pulled from the cabin rather than downstream of the temperature and humidity control system (THC) condensing heat exchanger $(\mathrm{CHX})$, testing to determine desiccant bed breakthrough in the powersave mode, and characterization of the cyclic humidity spike. There is concern that liquid water droplets possibility carried over from the $\mathrm{CHX}$ will poison the desiccant beds with resulting degradation in $\mathrm{CO}_{2}$ removal. An alternative is to pull 4BMS process air from the cabin or from inside the AR rack. When the 4BMS is operated in the powersave mode with a sorbent bed heater setpoint of $127^{\circ} \mathrm{C}$, the water breakthrough in the desiccant beds will eventually occur. No testing has been conducted to determine when the desiccant beds break through and need to be regenerated. Testing will characterize the humidity spike caused by desorption of the desiccant beds.

STAGE 10 WATER RECOVERY TEST-The development of the ISS water recovery and management (WRM) is supported through integrated ECLSS testing at MSFC. This testing, with development hardware integrated with end-use equipment, began in 1986 with Stages 1 through 10 completed at present (figure 6). The water recovery test (WRT) stage $9[9,10]$ tested the latest water recovery design for the ISS. This test operated for 116 days and concluded in January 1995. 


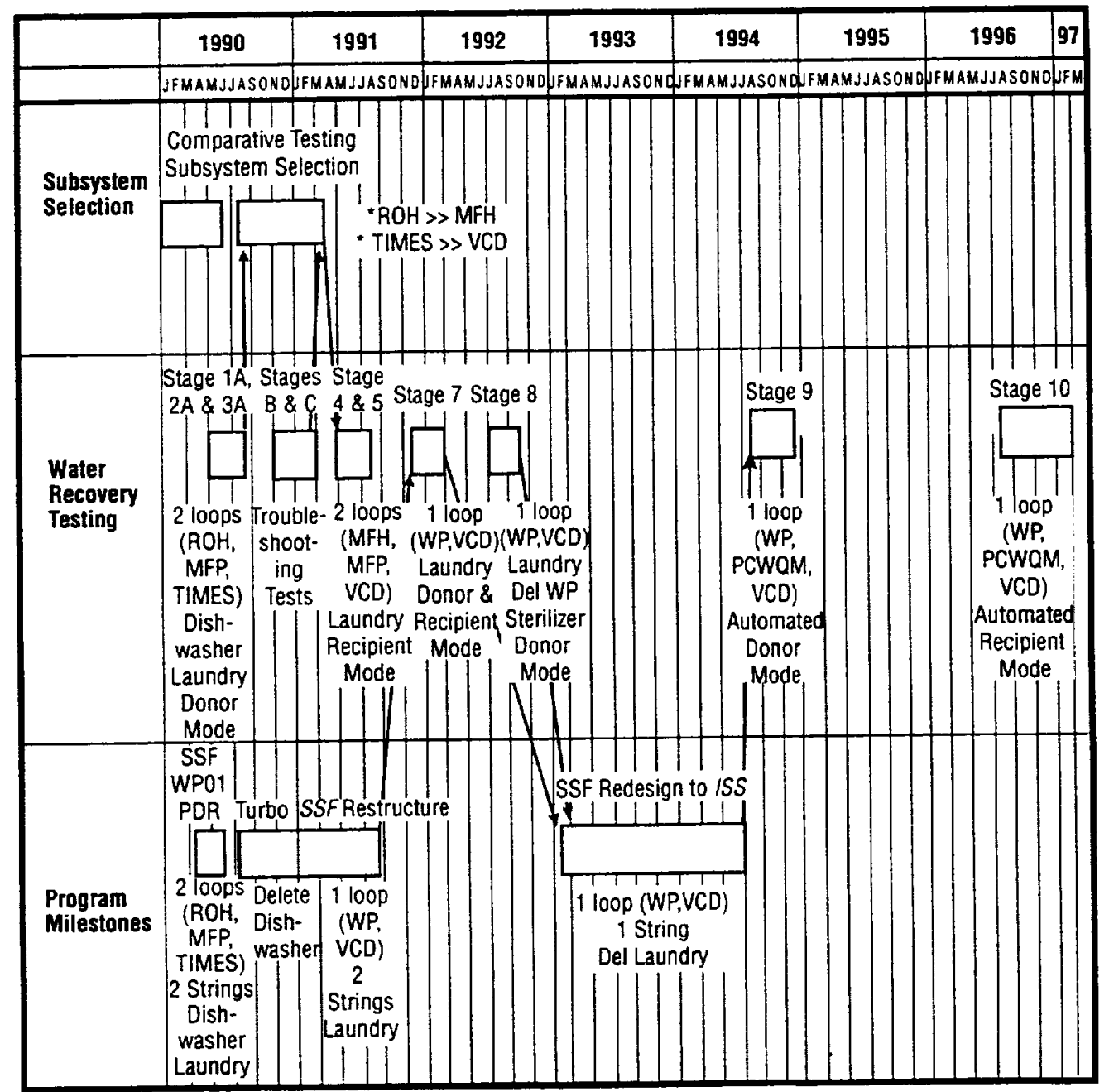

FIGURE 6.-MSFC water recovery test history.

The WRT stage 10 [11] evaluated automated, recipient-mode operation of the ISS WRM system for an extended duration. This test also evaluated the impact of several hardware and software modifications on the overall system performance. A schematic of stage 10 water recovery system integrated with End-use equipment is shown in figure 7 .

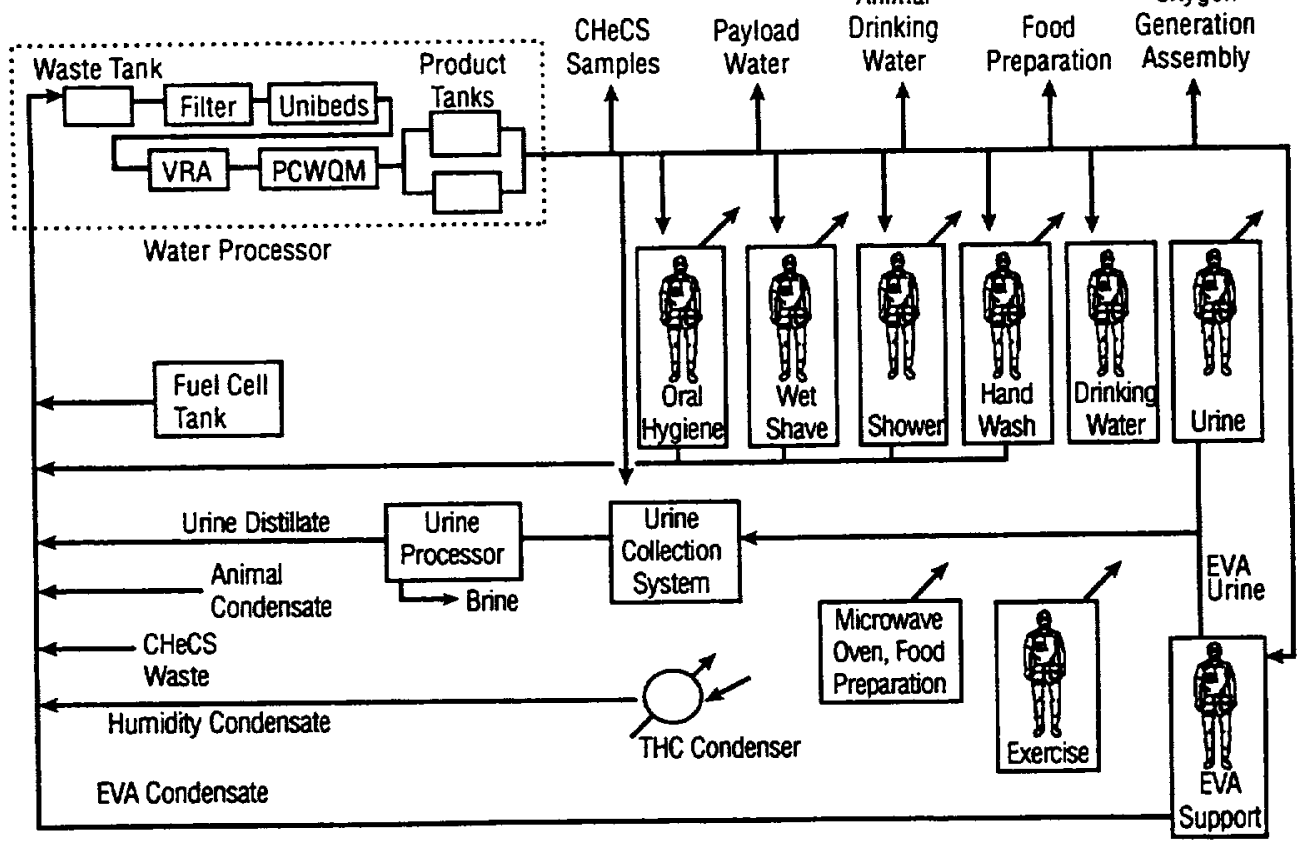

Figune 7.-Stage 10 water recovery test configuration. 
The WRT Stage 10 began on October 1, 1996 and ended on March 27, 1997 with 146 days of testing completed. Recipient mode testing was conducted through March 3 (128 test days) with the remainder of the test in donor mode. A viral challenge test, in cooperation with the Environmental Protection Agency, was conducted March $3-7,1997$. The test data are currently being analyzed, but preliminary findings include:

- Water quality consistently met the potable specification .

- The overall assessment of the water quality by the test subjects was that the water is more than acceptable for hygiene and potable use.

- The urine pretreatment tablet method provided the same level of pretreatment as the manual method.

- The operational life of the WP prefilter and the second Unibed were reduced due to the presence of high levels of zinc in the water system. The source of the zinc was the coating employed by the THC CHX. Further analysis and potential design modifications will be required to improve the life of these expendables.

- The WP gas/liquid separator failed during the test due to a chemical reaction with a trace contaminant. A potential redesign of the separator may be required depending on the source of the contaminant.

- The VCD urine processor experienced two anomalies, one related to the compressor gears and the other associated with the fluids pump. Workarounds were developed so that the VCD remained operational throughout the test.

A stage 11 test will be conducted starting in the summer of 1998 with the primary objective of further evaluating WRM hardware and design issues. This test will address design issues discovered as the result of the stage 10 testing.

\section{ECLSS LIFE TESTING}

Testing conducted to determine life characteristics include both subsystem and component level testing. Subsystems tested include the four bed molecular sieve, trace contaminant control subassembly (TCCS), Solid polymer electrolyzer (SPE) oxygen generator, and vapor compression distillation (VCD) urine processor. Component level life testing include the major constituent analyzer (MCA), water degradation study and WRM biofilm tests.

FOUR BED MOLECULAR SIEVE-The 4BMS life test unit startup was achieved in January, 1993 with the test continuing until November 1995 when sorbent bed heat- ers failed. The test determines the life characteristics of the desiccant bed and $\mathrm{CO}_{2}$ bed material. There has been no noticeable degradation in performance of the bed material after 19,872 hours of testing.

A significant finding of this test [12] was that some the adsorbent material was migrating past the containment screens and coating the internal surface with dust. The flight containment design was updated to include a finer mesh screen and batting material, in addition to a bead of silicon sealant to provide a continuous seal that prevented the material from leaving the sorbent bed.

The 4BMS life test resumed in January, 1997 after delivery and replacement of the sorbent bed heaters. A flightlike blower is being procured for installation in the subsystem. This test will continue with bed material and blower life being monitored.

TRACE CONTAMINANT CONTROL SUBASSEMBLY - The TCCS life test began in November 1992 and concluded in January 1995. The purpose was to test the TCCS high temperature catalyst for its thermal stability. No degradation in catalyst performance was noted after 18,288 hours of testing.

The test [13] showed that the TCCS high temperature catalyst life was longer than previously estimated. While the ISS logistics plan calls for the catalyst replacement every 180 days, this life test showed that under non-poisoning conditions the catalyst will remain effective for more than 2 years.

A TCCS catalyst poisoning test [14] investigated catalyst poisoning using a subscale bench test. The ISS catalyst was exposed to various poisoning agents at different concentrations. Test results indicated that catalyst material was poisoned by dichloromethane, Freon-113, and Halon-1301 but was easily regenerated with pure air at operating conditions of the catalyst. Hydrogen sulfide irreversibly poisons the catalyst but is readily adsorbed by stainless steel at operating conditions. This testing, in addition to the MSFC life testing, shows that the operational life of the TCCS catalyst can be extended to the life of the ISS.

SOLID POLYMER ELECTROLYZER OXYGEN GENERATOR-SPE oxygen generator testing at MSFC includes a 30 day performance test [15] conducted in 1995, limited daily testing February-May 1996, and an extended duration life test that began August 14, 1996 and is ongoing. This test identifies cell degradation or other long term effects. A plot of SPE average cell voltage versus test hours with significant test events is provided in figure 8 . There has been a steady rise in average cell voltage since the life test beginning. This anomaly is under investigation. 


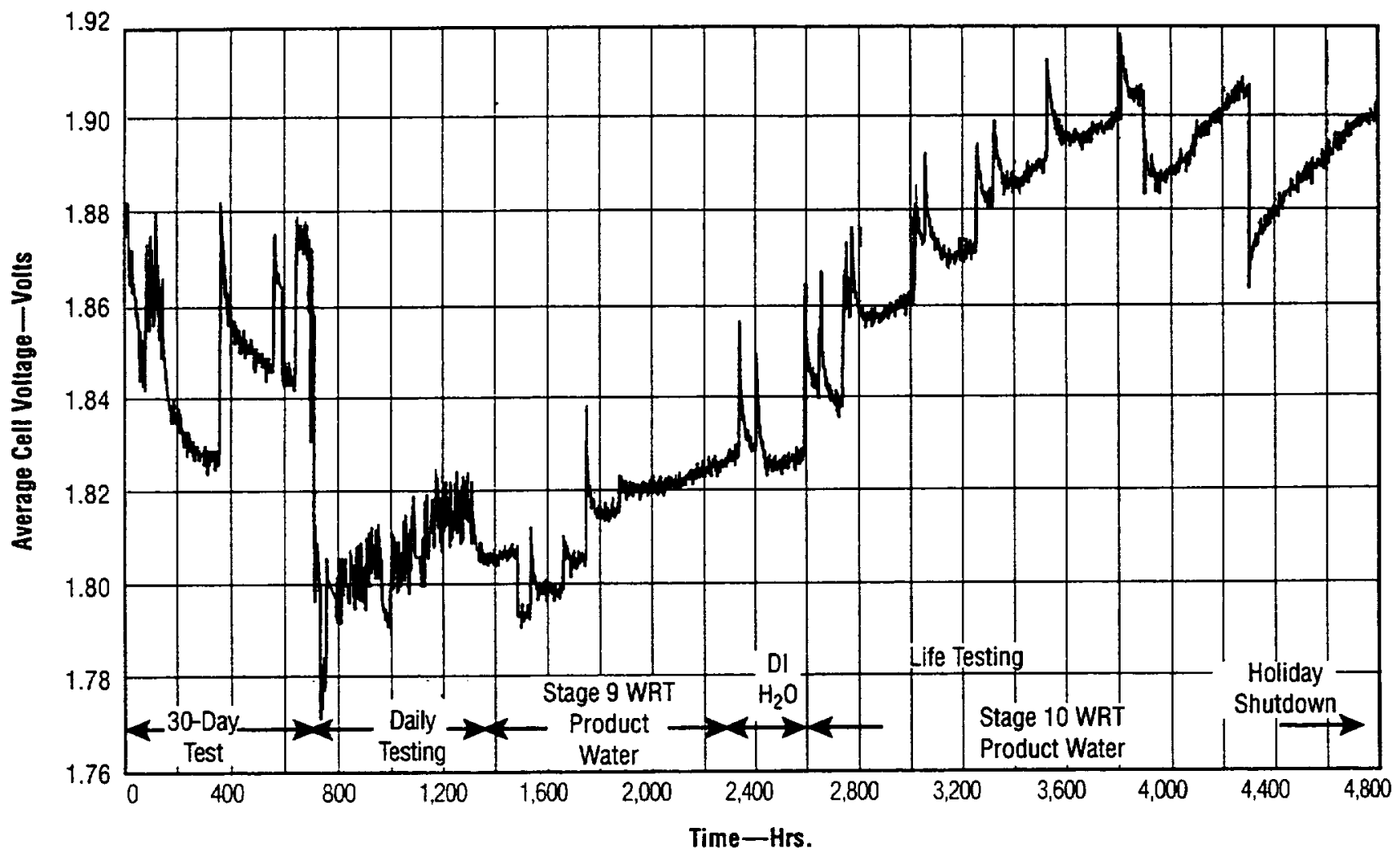

FIGURE 8.-SPE average cell voltage versus test time.

VAPOR COMPRESSION DISTILLATION URINE PROCESSOR-The VCD urine processor test began in January 1993 and was concluded in April 1996 for a total of 665 days $(3,342$ hours) of testing [16]. The purpose of the test was to determine mechanical wearout characteristics of the flight-like components. These included the peristaltic fluids pump, peristaltic purge pump, distillation unit, recycle filter tank, gas/liquid separator, and feed tank.

One significant anomaly was the failure of the flex spline in a gear reduction mechanism of the fluids pump drive shaft. The failure may have resulted from a slight horizontal misalignment introduced into the pump during retrofit at the hardware vendor. The hardware supplier has implemented use of a new alignment jig during hardware assembly to provide the proper alignment. The jig will be used for flight hardware assembly. A second pump problem was related to the tubing used in the peristaltic pump. Although it pumps a two-phase mixture which is mostly gas, this pump uses the same tubing as the fluids pump. This application caused tube spalling which results in the air/water separator clogging with tube material flakes. Eventually a VCD design change will be required to resolve this problem.

During the last half of 1995, the VCD experienced increasing problems such as excessive noise, increasing temperature, and high current loads. Upon disassembly in January 1996, the compressor gears and drive belt from the compressor to the drum had reached the end of their useful life and were replaced. The compres- sor gears and drive belt had operated for an estimated 4831 hours. After reassembly, the VCD exhibited a high current draw during startup after a period of no operation, such as a weekend. This problem persisted and the decision was made in April 1996 to return the subsystem to the hardware vendor for repair and installation of several flight-like components. This contracted effort was canceled due to unavailability of funding, and the subsystem is being rebuilt in-house at MSFC.

MAJOR CONSTITUENT ANALYZER-A test stand was delivered with four MCA filament assemblies and has been tested since July 1996. No evidence of degradation of performance has been noted to date. Concurrently a similar test stand containing eight sample pumps was delivered. Unfortunately it was determined that the pump design was changed after shipment of the test stands. An effort is underway to upgrade the sample pumps so they reflect the current ISS design. Upon completion of this upgrade, the test stand will be returned to MSFC and undergo life testing.

WATER DEGRADATION STUDY - The WDS began in January 1993 and is scheduled to be completed in January 1998. This test was initiated to investigate whether the WRM distribution line biocidal iodine would break down after the system was launched wet and remaining dormant for an extended time before activation.

The WDS consists of 34 tubes configured as straight sections, 10 feet long, with valves at each end. These tubes are grouped into two batches, designated batch 1 and batch 2 . Within each batch, the tubes are grouped 
into sets according to exposure time. All tubes are stored vertically in a rack until their exposure time is completed. Batch 1 includes both titanium and stainless steel tubes with stainless steel valves. Batch 2 includes only titanium tubes and valves. Batch 2 configuration testing began in January 1995.

Test results [17] demonstrates that water can be stored in a stainless steel or titanium distribution system for up to 24 months without significant levels of microbial growth. Data from the WDS suggests that there is an interaction between iodine and nickel (from the stainless steel valves) that results in depletion of up to 10 parts per million iodine within 3 to 6 months. Despite the rapid decrease in iodine concentrations, the WDS has not exhibited rampart microbial growth.
BIOFILM LIFE TEST-The Biofilm Life Test began in January 1997. The objective of the test [18] is to assess the extent of microbial growth and biofilm growth in the ISSWRM distribution lines and storage tanks.

The biofilm life test is composed of two similar setups (figure 9): one is filled with waste water and duplicates the conditions in the ISS water distribution lines and storage tanks prior to the Water Processor unibeds, and the other setup contains clean water distribution lines and storage tanks upstream of the points-of-use. For each setup, four titanium tubes and four SS tubes are arranged in parallel. Each tube contains bends to determine if the presence of bends affects the growth of microbes. Titanium, Inconel 718 , and SS coupons are suspended inside the storage tanks. Waste water for this test is generated in the MSFC EEF. Product water is simulated using facility deionized water seeded with microorganisms.

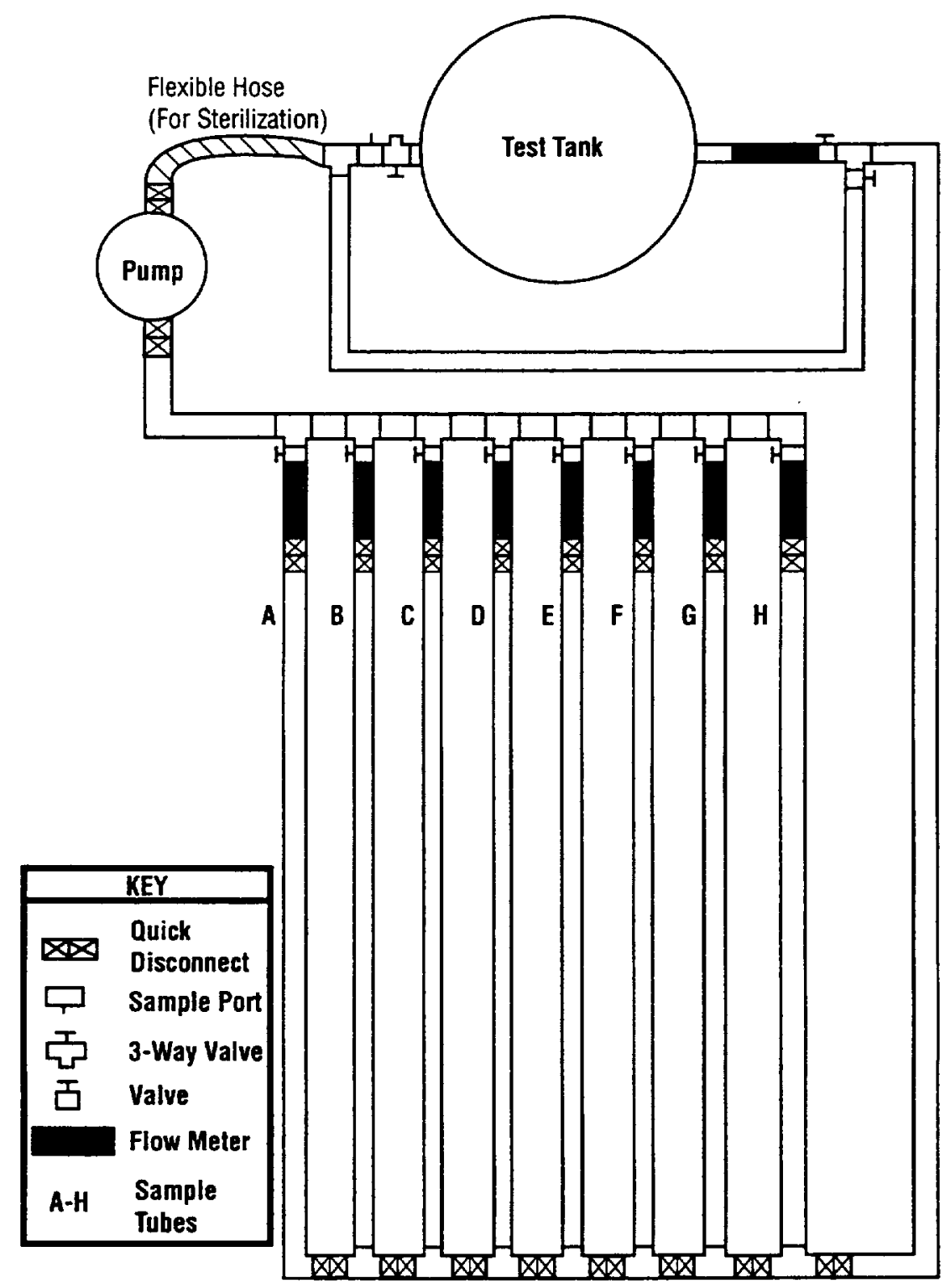

Figure 9.-Biofilm life test setup. 
Storage tank coupons and individual sample tubes will be periodically removed and analyzed for biofilm growth. Two tubes will be removed from both the clean and dirty water test setups at 6 month intervals. Storage tank coupons will be removed every 30 days during the first 6 months of testing and at 6 month intervals thereafter. Water samples will also be taken.

\section{ECLSS GOVERNMENT FURNISHED EQUIPMENT}

MANUAL PRESSURE EQUALIZATION VALVE (MPEV) SAMPLING ADAPTERS-Both an internal and external MPEV sampling adapter will be supplied to the ISS Program as government furnished equipment (GFE). The MPEV sampling adapters [19] consist of mechanical assemblies designed to sample the atmosphere and measure the pressure of an element or vestibule through the hatch MPEV prior to crew ingress on orbit. The MPEV external sampling adapter (ESA) is shown in figure 10. and wiil be attached to the hatch around the external side of the MPEV and will include a handle for opening the MPEV once the adapter is in place. A port is provided for the purposes of gas sampling and a pressure gauge to measure absolute pressure. The MPEV internal sampling adapter (ISA) shown in figure 11 will be attached via a vacuum access jumper to the vacuum access port on the internal side of the MPEV and will provide a port for gas sampling. An electronic pressure module, identical to the one that currently flies on shuttle, will interface with the shuttle fluke multimeter to measure absolute pressure.

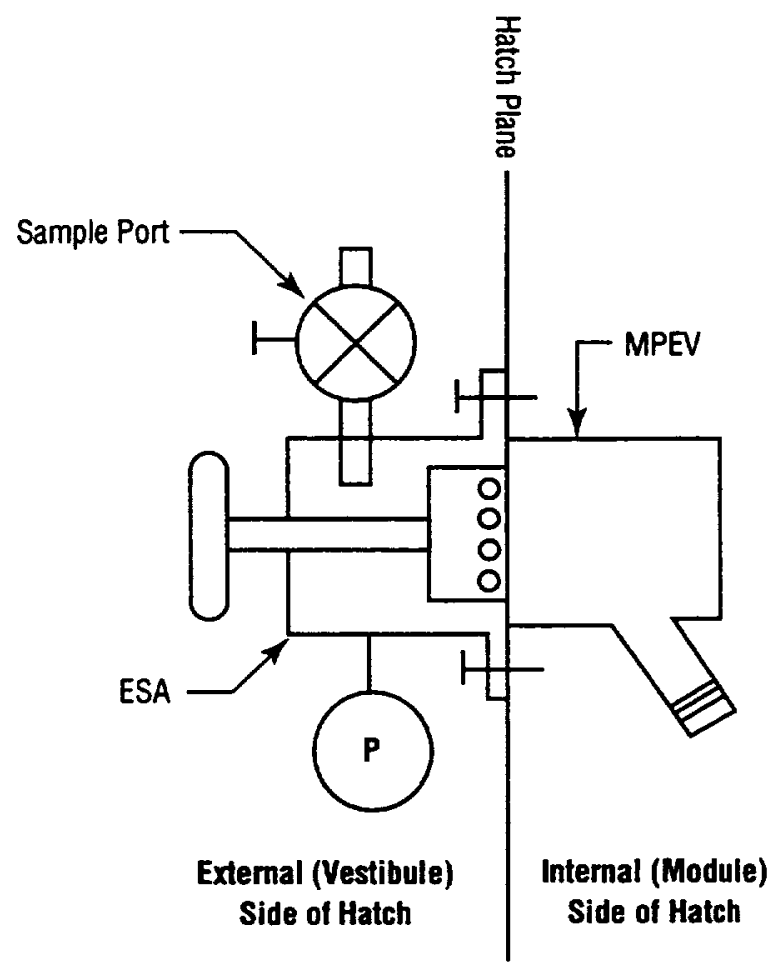

FIGURE 10.-MPEV external sampling adapter.

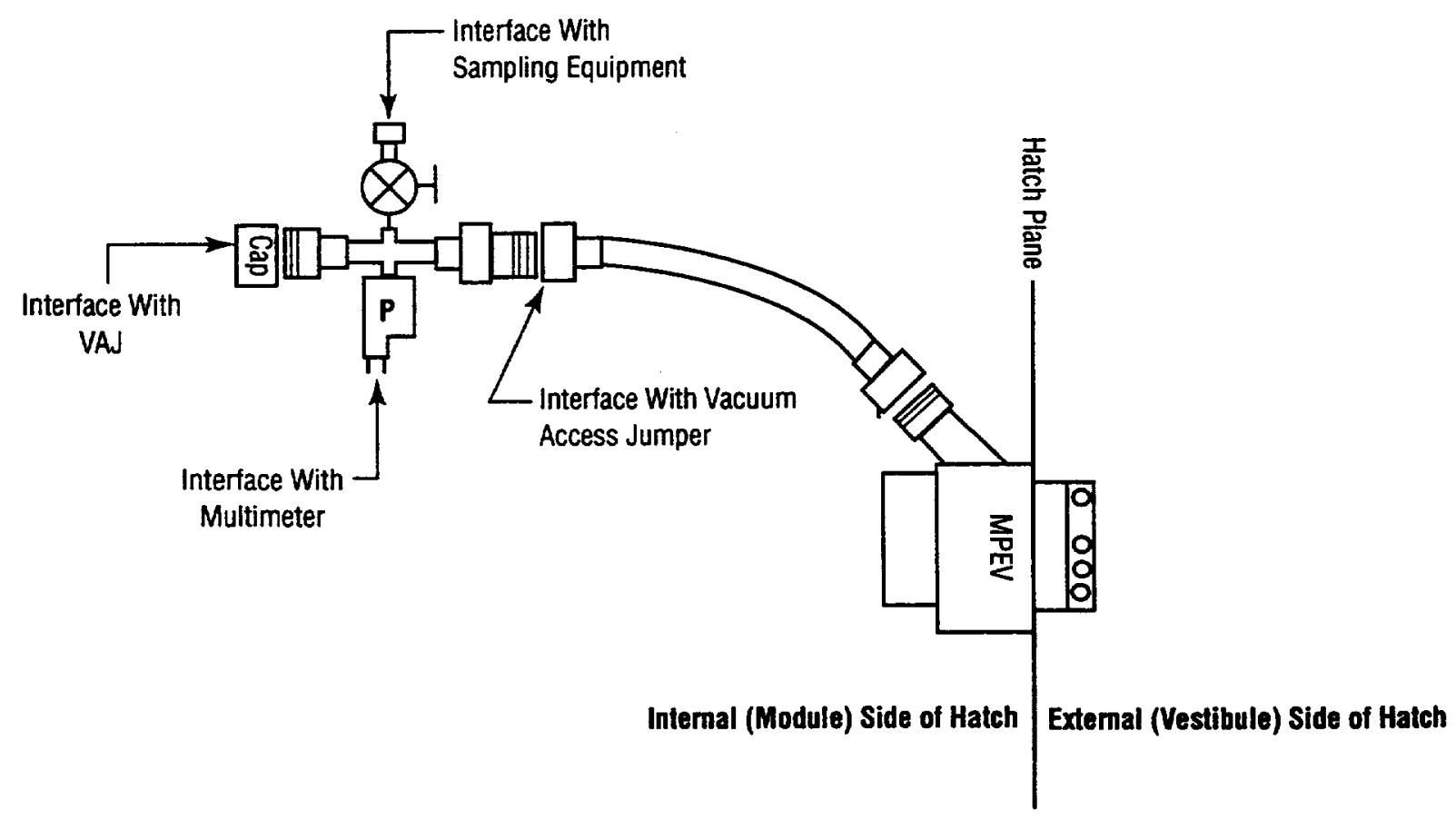

FIGURE 11.-MPEV internal sampling adapter. 
The MPEV ESA qualification testing has been completed with a Boeing need date of May 1997 with the qualification hardware to be used on Node 1 during ground transport to Kennedy Space Center. The current program need date for the flight units is August 1997 with first use on flight 3A scheduled for July 1998. The MPEV ISA qualification unit fabrication is underway with a current stated program need date of August 1997, although the first use is not until flight $3 A$.

\section{ECLSS TEST FACILITY LONG RANGE PLANS}

Plans are in work to evolve the existing MSFC ECLSS test facility into a functionally flight-like integrated ground test bed for use prior to and during ISS operation. If approved, this would provide the ISS program a functionally flight-like hardware/facility to address onorbit ECLSS contingency scenarios, troubleshooting, "what-if" exercises, support analyses, and a facility for development of evolutionary ECLSS hardware. Figure 12 depicts the concept of this evolution.

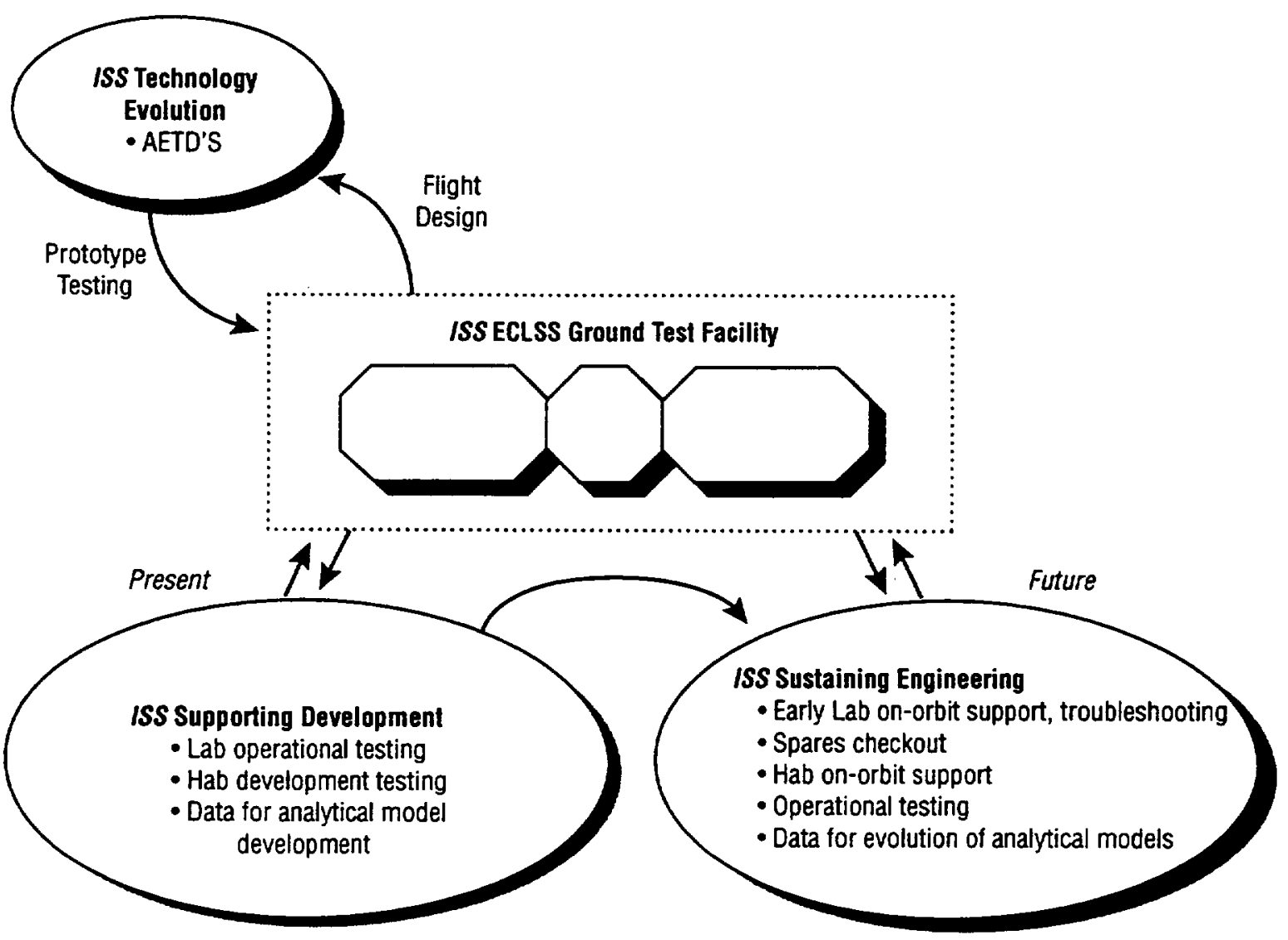

FIGURE 12.-ISS ECLSS ground test facility evolution.

INTEGRATED ECLSS GROUND TEST BED-The current MSFC ECLSS test facility configuration is shown in figure 13. It consists of the CMS, EEF, and the habitation module simulator. The CMS is used for AR testing, most recently for the ISS integrated AR test, and contains development quality AR hardware needed for testing. The EEF is utilized to generate the waste waters required for water reclamation testing. The EEF contains a shower, hand wash, exercise equipment, urinal, and a condensing heat exchanger for collection of human condensate. The Water Recovery subsystems are located around the EEF to minimize line runs from the collection points to the subsystems. The habitation module simulator (hab simulator), a new piece of test equipment, has not been utilized for ECLSS testing. 


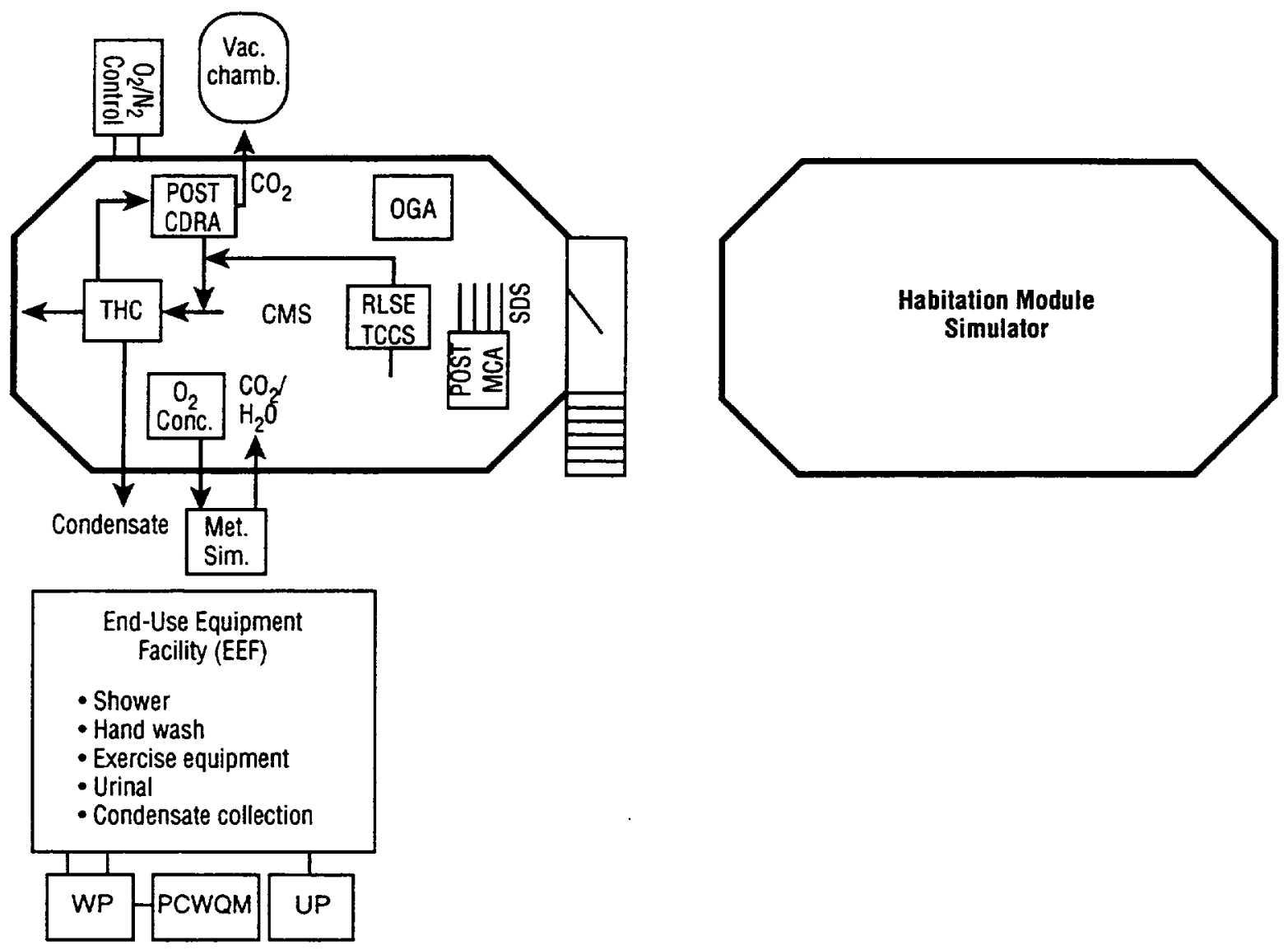

FIGURE 13.-Current MSFC ECLSS test facility.

The planned facility is shown in schematically in figure 14 and pictorially in figure 15 . The two modules will be connected with a "node" simulator. Ingress/egress to the hab simulator will be via an airlock since it would be utilized for the new EEF. A door will be added to one end of the CMS to facilitate ingress/egress.

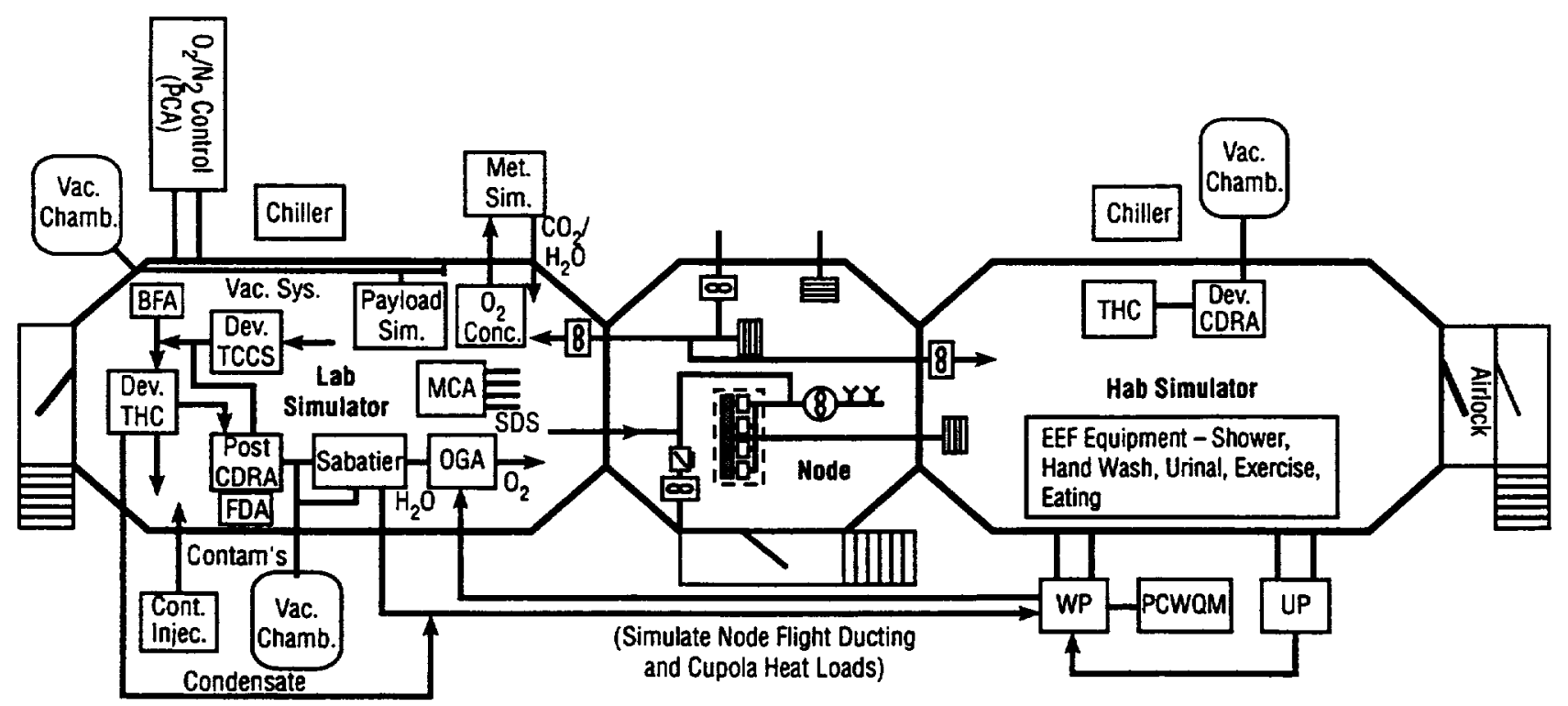

FIGURE 14.-Planned MSFC ECLSS test facility evolution. 


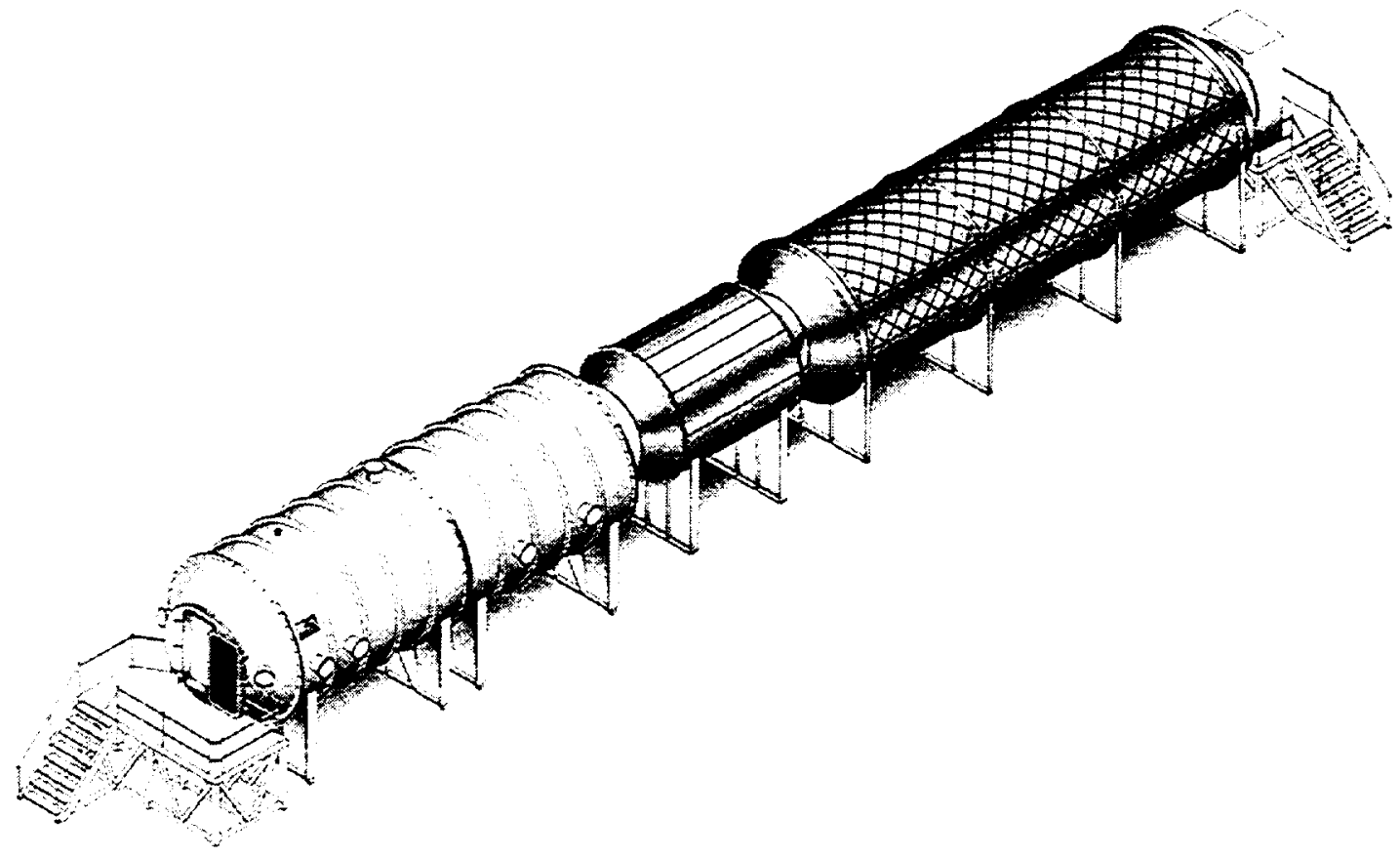

FIGURE 15.-ISS ECLSS ground test-bed concept.

The hab simulator will be outfitted with high fidelity development hardware. This will include a TCCS, THC, a fire detection assembly, pressure control assembly, and an ISS vacuum system. The THC and the carbon dioxide removal subsystem (CDRA) will be interfaced with flightlike ducting. The ISS sample delivery system (SDS) will be simulated and integrated with the MCA. The Sabatier carbon dioxide reduction subsystem will be installed to evolve the AR system into its final closed loop configuration. The condensate from the THC $\mathrm{CHX}$ will be routed to the WP for reclamation and reclaimed water provided back to the oxygen generator assembly.

The node simulator will be outfitted with high fidelity intermodule ventilation (IMV) hardware and node flight ducting and cupola heat loads simulated. A development CDRA will be obtained and installed in the hab simulator. EEF equipment will be installed in the hab simulator and interfaced with water reclamation hardware.

Upgrading this facility will provide the capability to support the ISS program in a more thorough manner under higher fidelity test conditions. This facility will contain a functionally flight-like AR system with flight-like THC/CHX ducting to support early laboratory module on-orbit operations. One possibility in this area will be ISS operational scenario testing such as the operation of two CDRA's to determine interactions between the two subsystems. There will be capability and existing interfaces to test habitation module AR hardware if needed for lab module troubleshooting. IMV ducting will be in place with the capability to check flow balancing, removal of heat loads generated in the cupola, and for troubleshooting other problems associated with the IMV system. A complete string of hab module development water system hardware integrated with end-use equipment utilizing human test subjects will be available for test purposes. There will be the capability to simulate toxic spills and the associated response of the ECLSS. The vacuum system with payload simulator location can be utilized to address leakage/venting issues. Oxygen closure development testing can be conducted to support hab module development efforts. Integrated testing with the THC, AR, and WRM subsystems with test subjects can be conducted if desired by the ISS program.

The hab simulator was recently moved into a permanent position, hard mounted to a support structure, and a floor installed. The hab simulator's mechanical and electrical design has been completed, as have specifications for component procurements. Work is continuing on outfitting the hab simulator, and it should be operational in the summer of 1998.

USE OF THE ECLSS TEST FACILITY FOR TECHNOLOGY DEMONSTRATION-MSFC submitted seven proposals [20] in response to the ISS Program Office Advanced Engineering Technology Development NASA Research Announcement. These proposals were categorized in the AR and WRM areas. These efforts would result in flight demonstration units to fly on the ISS. In addition, these efforts proposed development testing of the technology in the MSFC ECLSS test facility, with the exception of the process control water quality monitor (PCWQM).

The proposed efforts in the AR area include technology work on Sabatier $\mathrm{CO}_{2}$ reduction, high pressure oxygen generator, metal Monolith ${ }^{\mathrm{TM}}$ catalytic oxidizer for trace contaminant control, and an advanced $\mathrm{CO}_{2}$ removal system based on hydrophobic adsorbent. Work on the Sabatier $\mathrm{CO}_{2}$ reduction subsystem would include upgrading development hardware to resolve past technical issues, testing of 
the upgraded configuration, and finally development of a flight experiment design. A high pressure oxygen generator based on the SPE technology would be developed to support recharge of the high pressure oxygen tank used for extra vehicular activities. Metal Monolith ${ }^{\mathrm{TM}}$ catalytic reactor technology, developed under NASA's Small Business Innovative Research program, would be integrated into a development unit TCCS at MSFC to validate the integration concept. Based on the test data from this test, a prototype flight demonstration unit would be developed and delivered to the ISS program. Construction of a prototype $\mathrm{CO}_{2}$ remover based on a hydro- phobic adsorbent was also proposed. Adsorbent screening and advanced testing would be done at NASA Ames Research Center with the selected material used to develop a prototype unit for testing at MSFC.

The MSFC CMS was proposed to be utilized for testing of each AR prototype unit. A layout of the CMS is shown in figure 16, depicting placement of each prototype subsystem. Integration of these subsystems into the CMS would be simple since the existing facility interfaces could be utilized, as well as, a control and data management system. No additional facility buildup will be required.

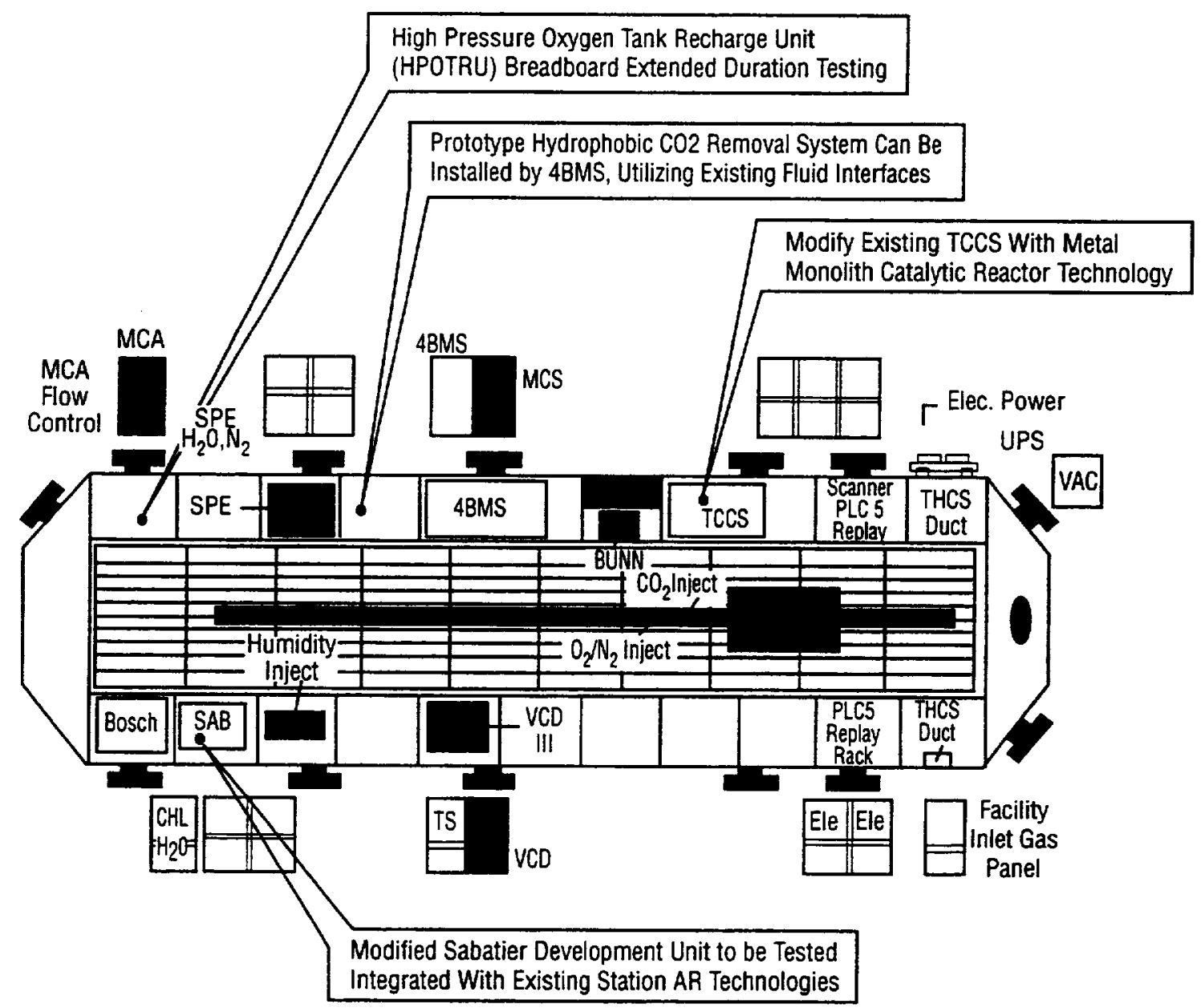

FIGURE 16.-Air revitalization technology evolution/integration with core module simulator.

The proposed efforts in the WRM area include technology work on the ISS WP, in-line microbial monitor, an advanced VCD urine processor, and a total organic carbon (TOC) PCWQM. The current ISS WP catalytic oxidation reactor would be modified to oxidize a wider range and higher concentration of organic compounds, allowing adsorption media from the WP Unibed ${ }^{\top M}$ to be reduced or removed. A polymerase chain reaction (PCR) in-line microbial monitor would be developed and a prototype unit integrated into the water recovery test setup at MSFC for further testing. The current VCD urine processor baseline would be modified by improving the design of the com- pressor gears and distillation drum. Upon validation of these improvements, orbital replacement units (ORU's) would be fabricated and replaced on-orbit. The development of the PCWQM TOC monitor would be completed which would provide an on-line TOC monitor for the ISS program.

The MSFC hab simulator was proposed to be utilized for testing of each WRM prototype unit with the exception of the PCWQM TOC monitor. The layout of the hab simulator shown in figure 17 indicates how the other prototype units would be integrated into the water recovery test system. As in the case of the AR prototypes, integration would be simple. 


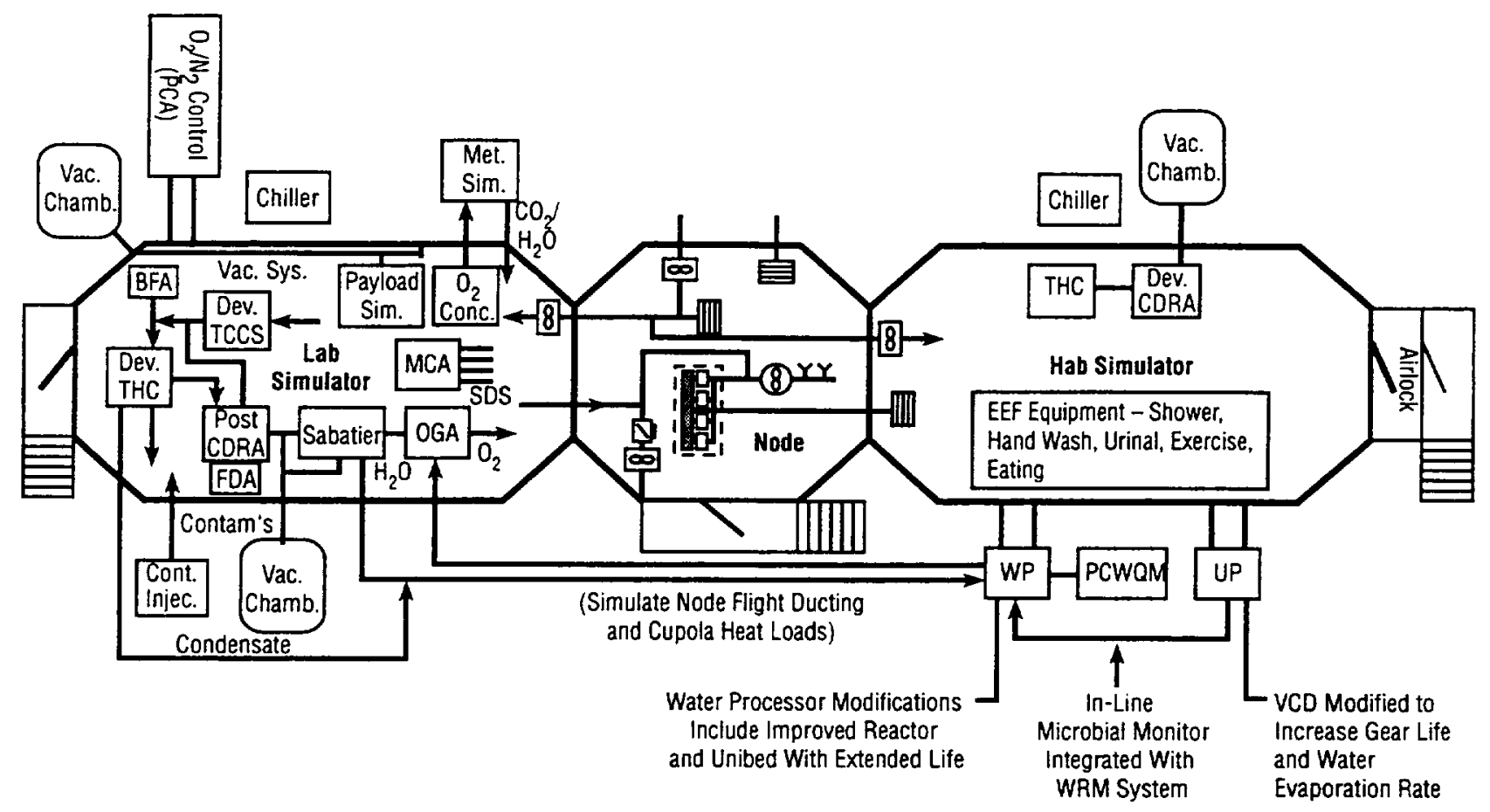

FIGURE 17.-Water reclamation technology evolution/integration with habitation module simulator.

\section{SUMMARY}

This paper summarizes ECLSS work currently being accomplished by the Marshall Space Flight Center under TTA's managed by the ISS Program Office. The ISS Program Office has asked MSFC to continue ECLSS supporting development efforts through the year 2000. These activities have been an asset to the ISS Program, because testing has uncovered numerous design problems which have been resolved early and work has been done on habitation module hardware that would not have otherwise been completed.

Additional work in the sustaining engineering and ECLSS technology development are also summarized. The MSFC ECLSS facility, which NASA has made a considerable investment during space station development, would be utilized for flight support and for development of evolutionary ECLSS hardware. This facility and the experienced personnel at MSFC have the capability to support both development and sustaining engineering activities in parallel at a minimal cost to the program.

\section{REFERENCES}

1. Ray, C.D. and Minton-Summers, S.: "International Space Station ECLSS Technical Task Agreement Summary Report." NASA TM-108508, Marshall Space Flight Center, AL, May 1996.

2. Bulloch, et al.: "Mathematical Modeling of Adsorption Processes for the International Space Station Alpha (ISSA) Water Processor." SAE 951629, 25th International Conference on Environmental Systems. San Diego, CA, July 10-13, 1995.
3. Clancey, et al.: "Ion Exchange Model Development for the International Space Station Alpha Water Processor." SAE 951628, 25th International Conference on Environmental Systems. San Diego, CA, July 10-13, 1995

4. Kindt, et al.: "Catalytic Oxidation Model Development of the Volatile Reactor Assembly Unit for the International Space Station Alpha (ISSA) Water Processor." SAE 951630 , 25th International Conference on Environmental Systems. San Diego, CA, July 10-13, 1995

5. Mohamadinejad, H., Smith, J.E., Knox, J.C., Finn, J.E.: "Hardware-Independent-Mathematical and Numerical Modeling of a Four Bed Molecular Sieve Part 1: Modeling and Verification of Gas Adsorption on Zeolite 5A." SAE 961405,26 th International Conference on Environmental Systems. Monterey, CA, July 8-11, 1996.

6. Knox, J.C.: "Performance Enhancement Test Preliminary Report"; ED62 (141-96), Marshall Space Flight Center, AL, October 1996.

7. Perry, J.L., et al.: “ International Space Station Integrated Air Revitalization Test." SAE 961519, 26th International Conference on Environmental Systems. Monterey, CA, July 8-11, 1996.

8. Kay, Robert: "Carbon Dioxide Removal Rate and Electrical Power Consumption Evaluation." Allied Signal Report 96-68476, Allied Signal Aerospace, Torrance, CA, April 18, 1996.

9. Carter, D.L., Holder, D.W., and Hutchens, C.F.: "International Space Station Environmental Control and Life Support System Phase III Water Recovery Test Stage 9 Final Report." NASA TM-108498, Marshall Space Flight Center, AL, Sept. 1995.

10. Carter, D.L.; Holder, D.W.; and Hutchens, C.F.: "Phase III Integrated Water Recovery Testing at MSFC: ISSA Configuration Test Results and Lessons Learned." 
SAE 951586, 25th International Conference on Environmental Systems. San Diego, CA, July 10-13, 1995

11. Carter, D.L.: "Water Recovery Test Stage 10 Test Requirements." ED62 (92-96), Marshall Space Flight Center, AL, June 1996.

12. Perry, J.L.: "Environmental Control and Life Support System (ECLSS) Life Test Program Interim Status." ED62 (45-94), Marshall Space Flight Center, AL, September 1994.

13. Tatara, J.D., and Perry, J.L.: "International Space Station Alpha Trace Contaminant Control Subassembly Life Test Final Report." NASA TM-108488, Marshall Space Flight Center, AL, March 1995.

14. Wright, J.D.; Chen, B.; Wang, C.; Perry, J.; and Tatara, J.D.: "An Investigation of International Space Station Trace Contaminant Oxidation Catalyst Poisoning." SAE 961517, 26th International Conference on Environmental Systems; Monterey, CA, July 8-11, 1996.

15. Erickson, R.E.; Roy, R.; Mason, R.; and Tatara, J.D.: "Solid Polymer Electrolysis Oxygen Generator Testing at MSFC." SAE 961518, 26th International Conference on Environmental Systems. Monterey, CA, July 8-11, 1996.

16. Chiu, C.; Salyer, B.; and Tatara, J.: "Environmental Control and Life Support Systems Life Test Quarterly Report 12." ION Electronics, Huntsville, AL, May 1996.

17. McRight, P. S., and Roman, M. C.: "Interim Report on the Space Station Water Degradation Study Covering the First 24 Months of Exposure." NASA TM-108499, Marshall Space Flight Center, AL, September 1995.

18. Roman, M.C.: "Test Plan for the Assessment of Biofilm Accumulation in the Water Distribution Lines and Storage Tanks of the International Space Station." ED62 (N)11-96), Marshall Space Flight Center, AL, Jan. 1996.

19. Carrasquillo, R.L.: "Manual Pressure Equalization (MPEV) Sampling Adapter Government Furnished Equipment (GFE) Project Implementation Agreement (PIA)." ED62 (21-95), Marshall Space Flight Center, AL, March 1995.

20. Littles, J.W.: "Proposal Transmittal Letter in Response to the Research Announcement for the Advanced Engineering and Technology Development for Application to the International Space Station (NRA 15-OG3-6-16P)." DA01, Marshall Space Flight Center, AL, June 1996. 